\title{
Toward an optimal spectral quality for plant growth and development: The importance of radiation capture
}

Bruce Bugbee ${ }^{1}$

1Department of Plants Soils and Climate, Utah State University, Logan, Utah, USA

\begin{abstract}
We have characterized the effects of individual wavelengths of light on single leaf photosynthesis but we do not yet fully understand the effects of multi-wavelength radiation sources on growth and whole-plant net assimilation. Studies with monochromatic light by Hoover, McCree and Inada nearly a half century ago indicated that blue and cyan photons are used less efficiently than orange and red photons. Contrary to these measurements, studies in whole plants have found that photosynthesis often increases with an increasing fraction of blue photons. Plant growth, however, typically decreases as the fraction of blue photons increases above 5 to $10 \%$. The dichotomy of increasing photosynthesis and decreasing growth reflects an oversight of the critical role of radiation capture (light interception) in the growth of whole plants. Photosynthetic efficiency is measured as quantum yield: moles of carbon fixed per mole of photons absorbed. Increasing blue light often inhibits cell division, cell expansion, and thus reduces leaf area. The thicker leaves have higher photosynthetic rates per unit area, but reduced radiation capture. This bluelight-induced reduction in photon capture is usually the primary reason for reduced growth in spite of increased photosynthesis per unit leaf area. This distinction is critical when extrapolating from single leaves to plant communities.
\end{abstract}

Keywords: photosynthetic efficiency, blue light, red light, green light, growth analysis, net assimilation rate, leaf area index, crop growth rate,

\section{Spectral effects on single leaf photosynthesis}

Although we have defined photosynthetic photon flux with equal weighting of all photons between 400 and $700 \mathrm{~nm}$, three studies indicate that this is not strictly correct in single leaves. Hoover (1937) used colored filters to achieve narrow spectra and determined spectral effects on photosynthesis in 29 species (Figure 1). He did not have the apparatus to determine radiation absorption, so his results were measured per incident photon. He found relatively sharp peaks in the blue and red regions and reported that differences among species were small.

Thirty-five years later, McCree (1972) and Inada (1976) revisited spectral effects on photosynthesis and quantum yield. Their response curves were developed from single leaves, at a low PPF, over a short time interval (minutes). Each of their studies included more than 20 species. Their studies confirmed the findings of Hoover (1937) and indicated only small differences among species. The differences among studies are significantly greater than differences among species within a study.

Both McCree and Inada found that, per absorbed photon, blue and cyan photons are used less efficiently than orange and red photons, but the quantum yield increased rapidly as the color of light changed from cyan to green (between 520 and $550 \mathrm{~nm}$ (Figure 1).

Measurement procedures were similar among studies but the study by McCree (1972a, b) includes the most comprehensive discussion of principles. Differences among studies indicate that

${ }^{1}$ E-mail: bruce.bugbee@usu.edu 
the McCree curve should not be considered a definitive reference for spectral quality and photosynthesis. More importantly, studies over longer time intervals now indicate that it may be inappropriate to use any of these curves to predict photosynthesis in whole plants under mixed colors of light at higher PPFs.


Figure 1. Spectral effects on photosynthesis from three studies: Hoover (1937), McCree (1972) and Inada (1976). All curves are redrawn from the original data. Black circles indicate wavelengths where measurements were made. The Hoover curve is per incident photon. The McCree and Inada curves are per absorbed photon, so they reflect the quantum yield of photosynthesis. The green light dip in the Hoover curve would be about $15 \%$ higher if it was per incident photon (increased from 0.6 to 0.7 ). 


\section{Determining whole plant photosynthesis from crop growth rate and leaf area index}

Plant growth analysis is widely used to separate crop growth rate (CGR; g dry mass per m2 ground area per day) into its two component parts: net assimilation rate (NAR; grams of dry mass per $\mathrm{m} 2$ of leaf per day) and leaf area index (LAI; leaf area index; $\mathrm{m} 2$ of leaf per $\mathrm{m} 2$ of ground Hunt (1982). The equation is:

$$
\text { CGR }=\text { NAR X LAI }
$$

Crop growth rate (biomass gain) and leaf area index are not difficult to measure. The ratio of CGR to LAI yields the integrated net assimilation rate over the measurement interval (NAR = CGR/LAI). This is the photosynthetic efficiency of the whole crop averaged over time (Fitter and Hay, 2012).

The NAR is related to single leaf photosynthetic rate $\left(\mathrm{P}_{\text {net }}\right)$, but there are important differences. Net photosynthesis in single leaves is typically determined by clamping a portion of a leaf in a chamber and measuring the uptake of $\mathrm{CO}_{2}$ over a short time interval (minutes). The unit of measurement is umol of $\mathrm{CO}_{2}$ per $\mathrm{m}^{2}$ leaf per second. This measurement is representative of the photosynthetic rate in part of a leaf at the PPF incident on the leaf at the time of measurement.

NAR integrates daily carbon gain and nighttime respiratory loss to provide a value for daily net whole-plant photosynthesis.

The development of portable photosynthesis systems in the 1980's resulted in widespread use of "clamp-on" photosynthesis measurements. These systems provide a rapid indication of photosynthetic rate and there has been great hope that these measurements would elucidate genetic and environmental effects on yield. Unfortunately, numerous studies over several decades have indicated that single leaf photosynthetic rate is poorly correlated with yield (see reviews by Evans 1993, 1998; and Long et al. 2006). While it is implicit that photosynthetic efficiency is essential to growth, this is the photosynthetic efficiency of the whole crop averaged over time. The problem is that short-term measurements of $P_{n e t}$ on single leaves poorly predict daily photosynthesis in whole plants.

\section{The importance of radiation capture efficiency}

Although NAR can be a more accurate predictor of environmental effects on whole-plant photosynthesis than short-term measurements of $\mathrm{P}_{\text {net, }}$, it is radiation capture efficiency (fraction of radiation intercepted) that is most closely related with biomass gain (Bugbee and Salisbury, 1988; Bugbee, 1995; Keating and Carberry, (1993); Monje and Bugbee, 1998). We know that increases in leaf area and radiation capture are often associated with thinner leaves in which NAR is reduced (Beadle and Long, 1985). In a classic study, Evans and Dunstone (1970) found that modern, highyielding wheat cultivars had lower leaf photosynthetic rates than their wild ancestors.

Since LAI determines radiation capture and is highly correlated with canopy photosynthesis and dry mass gain (Klassen et al. 2003), several studies have sought to separate radiation capture efficiency from canopy photosynthetic efficiency (Bugbee and Monje, 1992; Monje and Bugbee, 1998). It is apparent that improvements in radiation capture efficiency are responsible for nearly all of the increases in yield. Increases in biomass productivity are closely related to increased leaf area, and this usually results in decreased photosynthetic rate because of increased self-shading (Evans 1993).

\section{Spectral effects on single leaf photosynthetic efficiency}

In the quest to understand spectral effects on plant growth, several studies on have focused on single leaf photosynthetic efficiency over short time intervals. Numerous studies have examined the effects of increasing blue light on photosynthetic efficiency. Goins et al. (1997) and Yorio et al. (2001) demonstrated that some blue light was necessary for efficient photosynthesis. Hogewoning et al. (2010) found that increasing blue light from zero to $7 \%$ doubled the photosynthetic capacity, 
and that capacity in high light continued to increase up to 50\%. Terfa et al. (2013) showed that increasing blue light from 5 to $20 \%$ increased leaf thickness and increased photosynthetic capacity. Wang et al. (2015) found that stomatal conductance and net photosynthetic rate increased with increasing blue light in cucumber. Hernández and Kubota (2015) measured a 20\% increase in $P_{\text {net }}$ in cucumber as blue light fraction increased from 10 to 80\%. Ouzounis et al. (2014) and Ouzounis et al. (2015) reported, however, that there was no effect of blue light fraction on photosynthesis in roses, chrysanthemums and campanulas and lettuce. The results of these studies are in contrast to the spectral efficiency curves of Hoover (1937), McCree (1972) and Inada (1976), which indicate the blue light is used less efficiently in photosynthesis. It is apparent that other interacting factors alter the effect of light quality on photosynthetic efficiency in long-term studies.

\section{Effect of blue light fraction on growth}

Several studies indicate that growth (dry mass gain) decreases as the fraction of blue photons increases above about 5 to $10 \%$ blue photons. This has frequently been interpreted as an effect of increased blue light on reduced photosynthetic efficiency. This interpretation is nearly always incorrect. Photosynthetic efficiency is measured as quantum yield: moles of carbon fixed per mole of photons absorbed. Increasing blue light fraction inhibits cell division, cell expansion, and thus leaf area (Dougher and Bugbee, 2004). Reduced leaf area reduces photon capture. This blue-lightinduced reduction in photon capture is often the primary reason for reduced growth. There is often a minimal spectral effect on photosynthetic efficiency. This distinction is critical when extrapolating from single leaves to whole plants, to plant communities.

\section{Effect of blue light fraction on development}

Plant development is here defined as plant size and shape. A tall plant without branches might have the same growth (dry mass) as a short highly branched plant, but they have developed differently. Although wheat, and possibly all grasses, appears to have minimal sensitivity to spectral quality (Dougher and Bugbee, 2001); tomatoes are exquisitely sensitive; cucumbers, radishes and peppers have intermediate sensitivity; soybeans and lettuce have low sensitivity (Snowden et al. 2016). Blue light can alter secondary metabolism and these compounds provide protection from biotic and abiotic challenges. Blue light can interact with radiation intensity (PPF) and responses can change with developmental stage (Cope et al. 2013, 2014; Chen et al. 2014). The diversity of responses among species indicates that caution should be used in extrapolating from studies with Arabidopsis to crop plants. Similarities among groups of species, however, suggest that plants can be separated into categories by common responses.

\section{Effect of green light fraction on photosynthesis and growth}

Conclusions regarding the effect of green light range from detrimental to highly beneficial. Green light can alter plant development (Folta and Maruhnich 2007), although its effects may decrease as PPF increases (Wang and Folta 2013). Sun et al. (1998) found that red and blue light drive $\mathrm{CO}_{2}$ fixation primarily in the upper leaf layers while green light penetrates deeper and drives $\mathrm{CO}_{2}$ fixation in the lower leaf cells. Broadersen and Vogelmann (2010) measured chlorophyll fluorescence in leaf cross sections and showed that green light penetrated much deeper than red or blue light. Accordingly, once the upper part of individual leaves and the upper canopy as a whole are saturated, a higher fraction of green light should be especially beneficial (Nishio 2000). This effect was demonstrated by Terashima et al. (2009) who reported that in a high light background, green light drives leaf $\mathrm{P}_{\text {net }}$ more efficiently than red or blue light. Thus, whole plant $\mathrm{P}_{\text {net }}$ could be increased by green light penetration to lower leaf cells and lower leaf layers.

Some studies have suggested that a high green light fraction can improve plant growth. Kim et al. (2004) reported that supplementing red and blue LEDs with green light (from green 
fluorescent lamps) increased lettuce growth by up to $48 \%$ at the same total PPF. Their results indicated that too much (51\%) or too little $(0 \%)$ green light caused a decrease in growth, while about $24 \%$ was optimal.

Johkan et al. (2012) grew lettuce at three PPFs (100, 200, and $\left.300 \mu \mathrm{mol} \mathrm{m}^{-2} \mathrm{~s}^{-1}\right)$ using LEDs with cool white fluorescent controls at all three PPFs. As PPF decreased and the fraction of green light increased, the lettuce plants exhibited an increased shade-avoidance response. Plants grown under cool white fluorescent lamps developed more normally and grew faster than plants grown under the LEDs. These results are consistent with the findings of Kim et al. (2004).

In contrast to these studies, Hernández and Kubota (2015) found that the addition of $24 \%$ green light had no effect on growth (dry mass) of cucumbers.

In a comprehensive study with seven species, Snowden et al. (2016) studied the effect of blue and green light fractions at PPFs of 200 and $500 \mathrm{umol} \mathrm{m}^{-2} \mathrm{~s}^{-1}$. In contrast to some previous studies, growth (total dry mass) of three of the seven species was not reduced by a treatment with $93 \%$ green light compared to the broad spectrum, multi-wavelength treatments. Increasing blue light from 11 to $28 \%$, at a PPF of 500, reduced dry mass in tomatoes, cucumbers, radishes, and peppers, but there was no significant effect on soybeans, lettuce and wheat. At a PPF of 200 the reduction in dry mass from increasing blue light was only significant in tomatoes (Figure 2).

The Snowden et al. study (2016) used growth analysis techniques to determine integrated net assimilation rate (photosynthetic efficiency) over the 21 day growth cycle. NAR was determined by the ratio of dry mass gain divided by leaf area. There was no evidence of decreasing in photosynthetic efficiency, in any of the seven species, with increasing blue light, but photosynthetic efficiency increased with increasing blue light in cucumbers. These results suggest that the effect of blue light on reducing leaf area and radiation interception was the underlying cause of the reduction in growth.

Snowden et al. (2016) also found that increasing blue light had a greater effect at PPF 500 than at 200 for cucumbers, radishes and peppers, but there was no significant interactions between PPF and blue light fraction for the other four species.

Green light fractions in the Snowden study varied from zero to $30 \%$. In contrast to the significant responses to blue light, increasing green light fraction resulted in few significant differences, and there was no consistent direction of the effect among species or PPF levels (Figure 3). Collectively, these results indicate significant differences in sensitivity to blue light among species. The effects of blue light were mediated by changes in leaf area, with no significant effects on photosynthesis.

Contrary to several reports on significant green light effects on growth (both increases and decreases), Snowden et al. (2016) found no consistent effect of green light among species on growth or photosynthetic efficiency. 

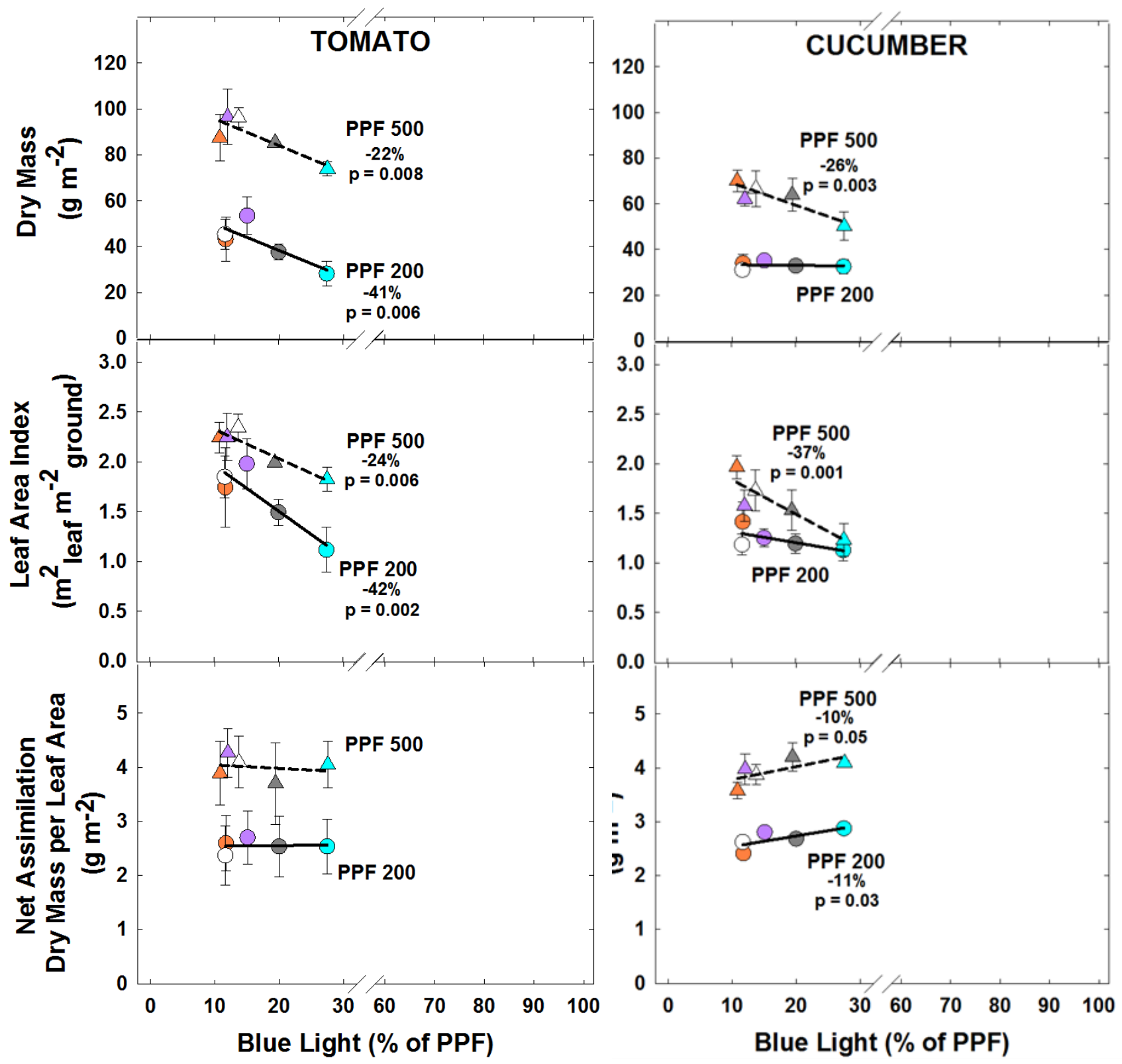

Figure 2. The effect of blue light on dry mass, leaf area index, and photosynthetic efficiency in tomatoes and cucumbers (data from Snowden et al. (2016). Both species are highly sensitive to blue light fraction. Photosynthesis likely increased in cucumbers because of decreased self-shading at the higher blue light fractions. 

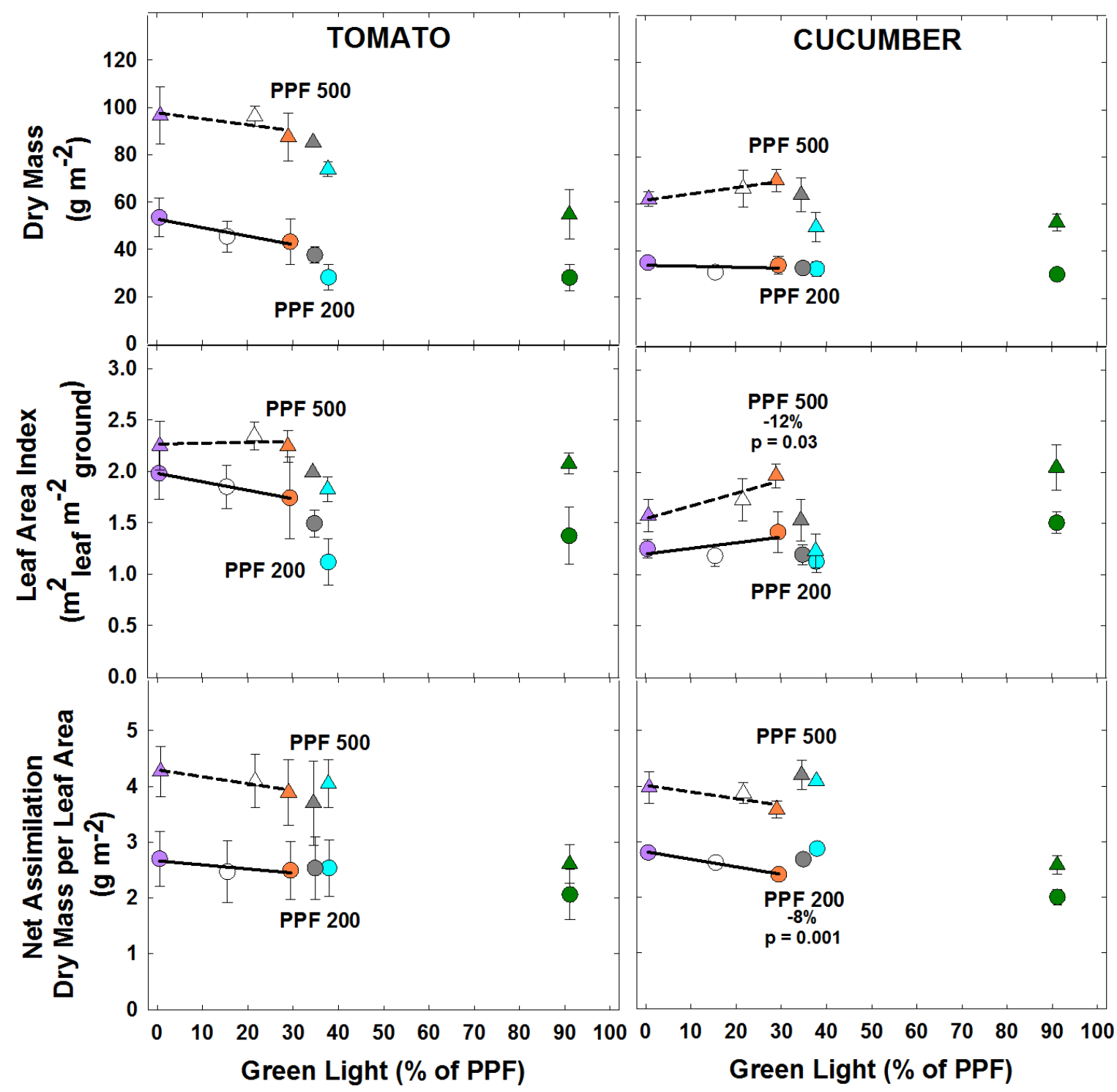

Figure 3. The effect of green light on dry mass, leaf area index, and photosynthetic efficiency in tomatoes and cucumbers. (data from Snowden et al. (2106). The green symbols represent light from green LEDs, which have $92 \%$ of their output between 500 and 600 $\mathrm{nm}$. The regression line connect treatments with blue, green, and red PPF fractions from LEDs. As the green light fraction increased the red light decreased.

\section{Electrical efficiency of HPS and LED technologies}

Nelson and Bugbee (2014) reported the photosynthetic (400-700 nm) photon efficiency and photon distribution pattern of multiple models of fixtures from four lighting technologies. The most efficient LED and HPS fixtures had nearly identical efficiencies at 1.66 to 1.70 micromoles per joule. They calculated the initial capital cost of fixtures per photon delivered and determined that LED fixtures cost five to ten times more than HPS fixtures. The five-year electric plus fixture cost per mole of photons was thus 2.3 times higher for LED fixtures, due to high capital costs. Compared to electric costs, their analysis indicated that the long-term maintenance costs were small for both technologies. A key advantage of LED fixtures is their ability to focus photons. They pointed out 
that if widely spaced benches are a necessary part of a production system, the unique ability of LED fixtures to focus photons on specific areas can be used to improve the photon capture by plant canopies. Figure 4 shows the economic cross over point for LED and HPS technologies. The lowest lighting system cost is realized when an efficient fixture is coupled with effective canopy photon capture.

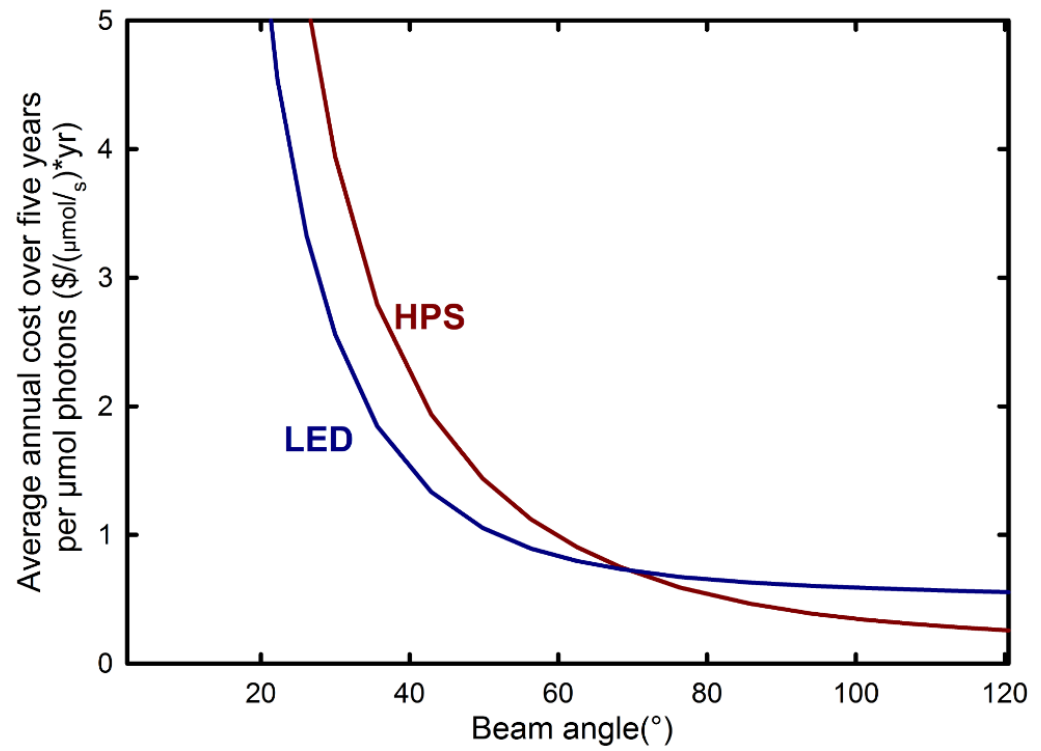

Figure 4. Effect of canopy photon capture efficiency on average annual cost over five years. The lowest cost of lighting is realized with 1000-W, double-ended, HPS technology when all of the radiation from a beam angle of 120 degrees can be utilized by the plant canopy. (reprinted with permission from Nelson and Bugbee 2014).

\section{Thermal effect of electric lighting technologies}

Large (600 watt) LED fixtures have become commercially available for both sole source (growth chamber) and supplemental (greenhouse) plant lighting. At the same time, the more traditional high pressure sodium (HPS) technology has improved in efficiency by as much as $60 \%$ (Nelson and Bugbee, 2014). The thermal properties of fixtures can change experimental outcomes, and alter heating and cooling costs.

The use of LED technology is commonly assumed to result in significantly cooler leaf temperatures than high pressure sodium technology. To evaluate the magnitude of this effect, Nelson and Bugbee (2015) measured radiation incident to and absorbed by a leaf under four radiation sources: clear sky sunlight in the field, sunlight in a glass greenhouse, and indoor plants under either high pressure sodium or light emitting diodes. They then applied a mechanistic energy-balance model to compare leaf to air temperature difference among the radiation sources and environments. At equal photosynthetic photon flux, their results indicated that the effect of plant water status and leaf evaporative cooling is much larger than the effect of radiation source. If plants are not water stressed, leaves in all four radiation sources were typically within $2{ }^{\circ} \mathrm{C}$ of air temperature. Under clear sky conditions, cool sky temperatures mean that leaves in the field are always cooler than greenhouse or indoor plants-when photosynthetic photon flux, stomatal conductance, wind speed, vapor pressure deficit, and leaf size are equivalent. As water stress increases and cooling via transpiration decreases, leaf temperatures can increase well above air 
temperature. In a near-worst case scenario of water stress and low wind, leaves can increase $6^{\circ}, 8^{\circ}$, $10^{\circ}$, and $12^{\circ} \mathrm{C}$ above air temperature under field, LED, greenhouse, and HPS scenarios, respectively. Because LED fixtures emit much of their heat through convection rather than radiative cooling, they result in slightly cooler leaf temperatures than leaves in greenhouses and under HPS fixtures, but the effect of LED technology on leaf temperature is smaller than is often assumed.

Compared to sunlight and HPS lamps, LED fixtures emit almost no near infrared radiation (NIR; 700-3000 nm), but this radiation is not well absorbed by plant leaves (Figure 5). Photosynthetic (400 to $700 \mathrm{~nm}$ ) and longwave (3,000 to $100,000 \mathrm{~nm}$ ) radiation are about $95 \%$ absorbed, but non-photosynthetic solar NIR is only about $20 \%$ absorbed, and has a smaller effect on leaf heating. Unabsorbed radiation is either transmitted or reflected.

A recent analysis showed that the conversion efficiency of electricity to photosynthetic photons of the most efficient commercial scale LED fixtures was equal to the most efficient HPS fixtures at $1.7 \mu \mathrm{mol}$ photosynthetic photos per joule of electrical input (Nelson and Bugbee 2014). They thus generate the same amount of thermal energy per photosynthetic photon. LED fixtures, however, LEDs dissipate much of their heat away from the plane they illuminate, while HPS fixtures dissipate more heat toward the plane they illuminate.
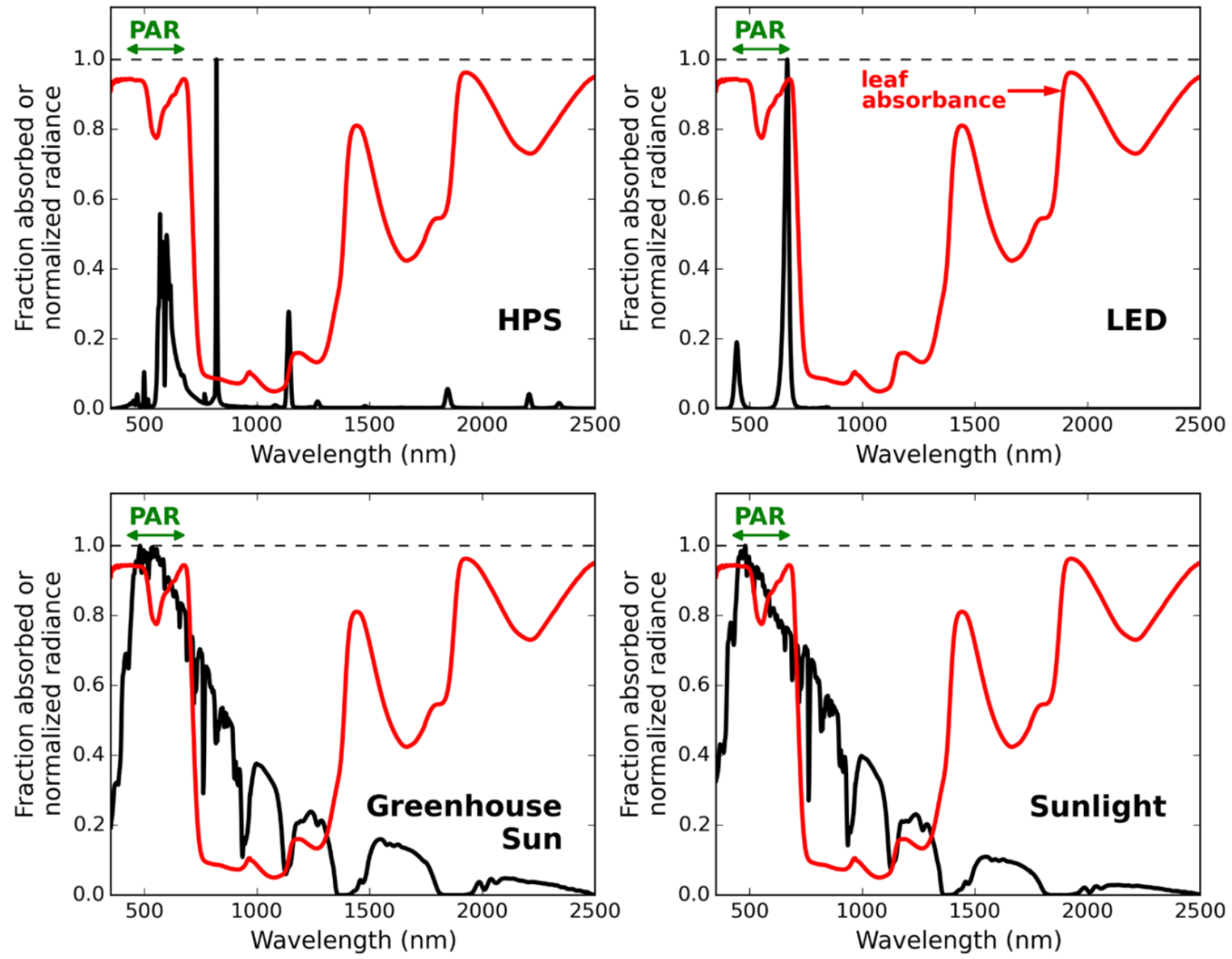

Figure 5. Radiance spectrum from four radiation sources (black line) and average leaf absorbance (red line). (reprinted with permission from Nelson and Bugbee , 2015). 
Nelson and Bugbee (2015) found that the leaf-to-air temperature difference, in all radiation scenarios, was less than $2^{\circ} \mathrm{C}$ except where parameters approached their extremes (Figure 6). The relative order did not change, regardless of environmental conditions, with HPS > greenhouse sun $>$ LED > clear sky sunlight.
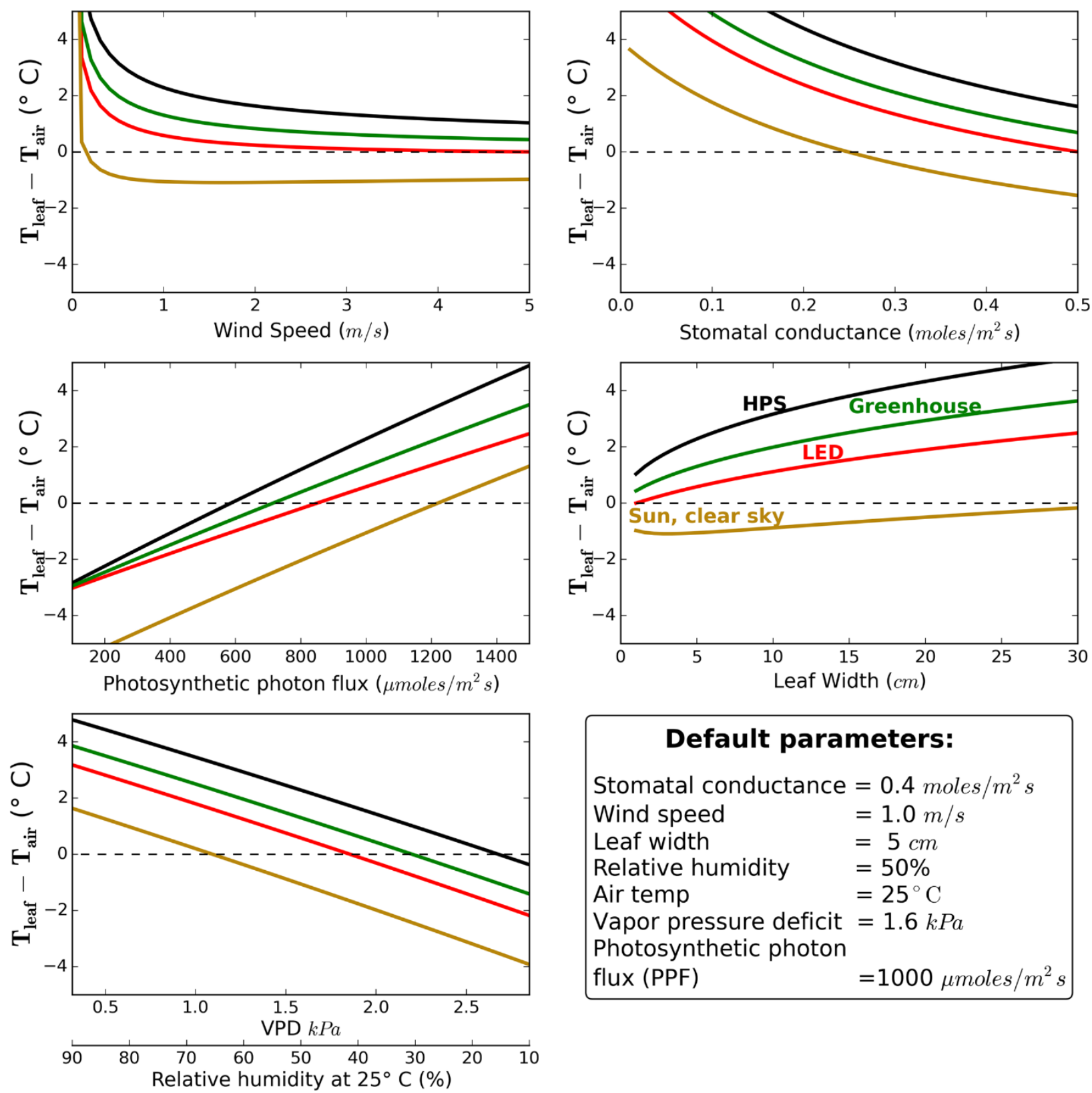

\section{Default parameters:}

Stomatal conductance $=0.4$ moles $/ \mathrm{m}^{2} \mathrm{~s}$ Wind speed $\quad=1.0 \mathrm{~m} / \mathrm{s}$ Leaf width $\quad=5 \mathrm{~cm}$ Relative humidity $\quad=50 \%$ Air temp $\quad=25^{\circ} \mathrm{C}$ Vapor pressure deficit $=1.6 \mathrm{kPa}$ Photosynthetic photon flux (PPF) $=1000 \mu \mathrm{moles} / \mathrm{m}^{2} \mathrm{~s}$

Figure 6. Calculated effects of environmental conditions on the difference between leaf temperature and air temperature under four radiation scenarios. (reprinted with permission from Nelson and Bugbee, 2015). 


\section{Thermal effects of elevated $\mathrm{CO}_{2}$}

Controlled environments often add supplemental $\mathrm{CO}_{2}$, which can decrease stomatal conductance $10-40 \%$ and increase leaf temperature. The analysis of Nelson and Bugbee (2015) indicates that a decrease in stomatal conductance of $30 \%$ in response to elevated $\mathrm{CO}_{2}$ would increase leaf temperature by $1^{\circ} \mathrm{C}$ in all radiation scenarios.

\section{Effect of light source on shoot tip temperature}

Shoot tip temperature is often used to predict time to flower and plant development rates. Nelson and Bugbee (2015) found that choice of lighting technology will likely affect shoot tip temperature, time to flower and plant development.

\section{Effect of light source on fruit and flower temperature}

The analysis of Nelson and Bugbee (2015) indicates that the near-worst case analysis would likely be representative of flowers, fruits, and thick, dense plant parts that have low transpiration rates, including high value products such as tomatoes, strawberries, and Cannabis flowers. These thicker structures would absorb more radiation than a thin leaf. Based on the analysis of Nelson and Bugbee (2015) LED technology has the potential to reduce heating of these thick, low transpiring plant structures. In conditions where leaves and shoot tips benefit from heating, such as a greenhouse in a cool climate, HPS technology would more effectively transfer heat to canopies.

\section{Literature cited}

Beadle C.L., and Long, S.P. (1985). Photosynthesis - is it limiting to biomass production? Biomass 8, 119-168 http://dx.doi.org/10.1016/0144-4565(85)90022-8.

Broadersen, C.R., and Vogelmann, T.C. (2010). Do changes in light direction affect absorption profiles in leaves? Functional Plant Biol. 37, 403-412 http://dx.doi.org/10.1071/FP09262.

Bugbee, B. (1995). The components of crop productivity: Measuring and modeling plant metabolism. Am. Soc. Gravitational Space Biol. 8, 93-104.

Bugbee B., and Salisbury, F.B. (1988). Exploring the limits of crop productivity: Photosynthetic efficiency in high irradiance environments. Plant Physiol. 88, 869-878 http://dx.doi.org/10.1104/pp.88.3.869.

Bugbee, B., and Monje, O. (1992). The limits of crop productivity: Theory and validation. BioScience 42, 494-502 DOI: $10.2307 / 1311879$.

Chen, X., Guo, W., Xue, X., Wang, L., and Qiao, X. (2014). Growth and quality responses of 'Green Oak Leaf' lettuce as affected by monochromic or mixed radiation provided by fluorescent lamp (FL) and light-emitting diode (LED). Sci. Hortic. 172, 168-175 http://dx.doi.org/10.1016/j.scienta.2014.04.009.

Cope, K., Snowden, M.C., and Bugbee, B. (2014). Photobiological interactions of blue light and photosynthetic photon flux: Effects of monochromatic and broad-spectrum light sources. Photochem. Photobiol. 90, 574-584 DOI: 10.1111/php.12233.

Cope, K.R., and Bugbee, B. (2013). Spectral effects of three types of white light-emitting diodes on plant growth and development: Absolute versus relative amounts of blue light. HortScience 48, 504-509.

Dougher, T.A.O., and Bugbee, B. (2001). Differences in the response of wheat, soybean, and lettuce to reduced blue radiation. Photochem. Photobiol. 73, 199-207 DOI: 10.1562/0031-8655(2001)0730199DITROW2.0.CO2.

Dougher, T.A.O., and Bugbee, B. (2004). Long-term blue light effects on the histology of lettuce and soybean leaves and stems. J. Am. Soc. Hort. Sci. 129, 467-472.

Evans, L.T. (1993). Crop Evolution, Adaptation and Yield. CUP, Cambridge, MA, USA. 
Evans, L.T. (1998). Greater crop production: Whence and whither? In Feeding a World Population of More Than Eight Billion People - A Challenge to Science, J.C. Waterlow, D.G. Armstrong, L. Fowdenand and R. Riley, eds., (Cary, NC, USA: Oxford University Press.), p. 89-97.

Evans, L.T., and Dunstone, R.L. (1970). Some physiological aspects of evolution in wheat. Australian J. Biol. Sci. 23, 725741 doi:10.1071/BI9700725.

Fitter, A., and R.M. Hay. (2012). Environmental Physiology of Plants, 3 $3^{\text {rd }}$ edn (London, UK: Academic Press), pp. 367.

Folta, K.M., and Childers, K.S. (2008). Light as a growth regulator: Controlling plant biology with narrow-bandwidth solid-state lighting systems. HortScience 43, 1957-1964.

Folta, K.M., and Maruhnich, S.A. (2007). Green light: A signal to slow down or stop. J. Exp. Bot. 58, 3099-3111 doi: $10.1093 /$ jxb/erm130.

Goins, G., Yorio, N., Sanwo, M., and Brown, C. (1997). Photomorphogenesis, photosynthesis, and seed yield of wheat plants grown under red light-emitting diodes (LEDs) with and without supplemental blue lighting. J. Expt. Bot. 48, 14071413 doi: $10.1093 / j x b / 48.7 .1407$.

Hernández, R., and Kubota, C. (2015). Physiological responses of cucumber seedlings under different blue and red photon flux ratios using LEDs. Environ. Expt. Bot. 121, 66-74 doi:10.1016/j.envexpbot.2015.04.001.

Hogewoning, S.W., Trouwborst, G., Maljaars, H., Poorter, H., van Ieperen, W., and Harbinson, J. (2010). Blue light doseresponses of leaf photosynthesis, morphology, and chemical composition of Cucumis sativus grown under different combinations of red and blue light. J. Expt. Bot. 61, 3107-3117 doi: 10.1093/jxb/erq132.

Hoover, W.H. (1937). The dependence of carbon dioxide assimilation in a higher plant on wave-length of radiation. Smithsonian Misc. Collections 95, 1-13.

Hunt, R. (1982). Plant growth analysis (Lavenham, Suffolk, UK: Lavenham Press Ltd.), pp. 8.

Inada, K. (1976). Action spectra for photosynthesis in higher plants. Plant Cell Physiol. 17, 355-365.

Johkan, M., Shoji, K., Goto, F., Hahida, S., and Yoshihara, T. (2012). Effect of green light wavelength and intensity on photomorphogenesis and photosynthesis in Lactuca sativa. Environ. Exp. Bot. 75, 128-133 http://dx.doi.org/10.1016/j.envexpbot.2011.08.010.

Keating, B., and Carberry, P. (1993). Resource capture and use in intercropping: Solar radiation. Field Crops Res. 34, 273-301 http://dx.doi.org/10.1016/0378-4290(93)90118-7.

Kim, H.-H., Goins, G., Wheeler, R., Sager, J.C., and Yorio, N.C. (2004). Green-light supplementation for enhanced lettuce growth under red and blue LEDs. HortScience 39, 1616-1622.

Klassen, S.P., Ritchie, G., Frantz, J.M., Pinnock, D., and Bugbee, B. (2003). Real time imaging of ground cover: Relationships with radiation capture, canopy photosynthesis, and daily growth rate. In Digital Imaging and Spectral Techniques: Applications to Precision Agriculture and Crop Physiology (Am. Soc. Agron. Special Publication No. 66.: Madison, WI), p. 3-14 doi:10.2134/asaspecpub66.c1.

Long, S., Zhu, X., Naidu, S.L., and Ort, D. (2006). Can improvement in photosynthesis increase crop yields? Plant, Cell Environ. 29, 315-330 DOI: 10.1111/j.1365-3040.2005.01493.x.

McCree, K.J. (1972a). The action spectrum absorptance and quantum yeild of photosynthesis in criop plants. Agric. Meteorol. 9, 191-216 http://dx.doi.org/10.1016/0002-1571(71)90022-7.

McCree, K.J. (1972b). Test of current definitions of photosynthetically active radiation against leaf photosynthesis data. Agric. Meteorol. 10, 443-453 http://dx.doi.org/10.1016/0002-1571(72)90045-3.

Monje, O., and Bugbee, B. (1998). Adaptation to high $\mathrm{CO}_{2}$ concentration in an optimal environment: Radiation capture, canopy quantum yield, and carbon use efficiency. Plant Cell Environ. 21, 315-324 DOI: 10.1046/j.1365-

3040.1998.00284.x. 
Nelson, J., and Bugbee, B. (2015). Analysis of environmental effects on leaf temperature under sunlight, high pressure sodium and light emitting diodes. PLOS ONE DOI: 10.1371/journal.pone.0138930.

Nelson, J., and Bugbee, B. (2014). Economic analysis of greenhouse lighting: Light emitting diodes vs. high intensity discharge fixtures. PLOS ONE DOI:10.1371/journal.pone.0099010.

Nishio, J.N. (2000). Why are higher plants green? Evolution of the higher plant photosynthetic pigment complement. Plant, Cell Environ. 23, 539-548 DOI: 10.1046/j.1365-3040.2000.00563.x.

Ouzounis, T., Frette, X., Rosenqvist, E., and Ottosen, C-O. (2014). Spectral effects of supplementary lighting on the secondary metabolites in roses, chrysanthemums, and capanulas. J. Plant Physiol. 171, 1491-1499 http://dx.doi.org/10.1016/j.jplph.2014.06.012.

Ouzounis, T., Parjikolaei, B.R., Fretté, X., Rosenqvist, E., and Ottosen, C.-0. (2015). Predawn and high intensity application of supplemental blue light decreases the quantum yield of PSII and enhances the amount of phenolic acids, flavonoids, and pigments in Lactuca sativa. Frontiers Plant Sci. 6, 19 http://dx.doi.org/10.3389\%2Ffpls.2015.00019.

Snowden, M.C., Cope, K., and Bugbee, B. (2016). Sensitivity of seven diverse species to blue and green light: Interactions with photon flux. In review.

Sun, J., Nishio, J.N., and Vogelmann, T.C. (1998). Green light drives CO2 fixation deep within leaves. Plant Cell Physiol. 39, 1020-1026. doi: 10.1093/oxfordjournals.pcp.a029298.

Terashima, I., Fujita, T., Inoue, T., Chow, W.S., and Oguchi, R. (2009). Green light drives leaf photosynthesis more efficiently than red light in strong white light: Revisiting the enigmatic question of why leaves are green. Plant Cell Physiol. 50, 684-697 doi: 10.1093/pcp/pcp034.

Terfa, M.T., Solhaug, K.A., Gislerød, H.R., Olsen, J.E., and Torre, S. (2013). A high proportion of blue light increases the photosynthesis capacity and leaf formation rate of Rosa $\times$ hybrida but does not affect time to flower opening. Physiol. Plantarum. 148, 146-159 DOI: 10.1111/j.1399-3054.2012.01698.x.

Wang, X.Y., Xu, X.M., and Cui, J. (2015). The importance of blue light for leaf area expansion, development of photosynthetic apparatus, and chloroplast ultrastructure of Cucumis sativus grown under weak light. Photosynthetica 53, 213-222 DOI: 10.1007/s11099-015-0083-8.

Wang, Y., and Folta, K.M. (2013). Contribution of green light to plant growth and development. Am. J. Bot. 100, 70-78 doi: 10.3732/ajb.1200354.

Yorio, N.C., Goins, G., Kagie, H., Wheeler, R., and Sager, J.C. (2001). Improving spinach, radish, and lettuce growth under red LEDs with blue light supplementation. HortScience. 36, 380-383.

Zhang, T., Maruhnich, S.A., and Folta, K.M. (2011). Green light induces shade avoidance symptoms. Plant Physiol. 157, 1528-1536 doi: 10.1104/pp.111.180661. 